\title{
P-0375 Efficacy and safety of switching from basal insulin to once-daily insulin IDegAsp in Japanese patients with T2DM
}

Yoshio Nagai, Yuta Nakamura, Ayumi Tenjin, and Yasushi Tanaka

Metabolism and Endocrinology, Internal Medicine, St. Marianna University School of Medicine

\section{《Background》}

Basal insulin-supported oral therapy (BOT) is commonly used to initiate insulin therapy when oral hypoglycemic agents do not achieve adequate glycemic control in patients with Type 2 diabetes. While supplementing basal insulin is expected to reduce the fasting plasma glucose level, some patients still fail to achieve the target hemoglobin A1c (HbA1c), probably due to postprandial hyperglycemia. Elevated postprandial glucose levels make an important contribution to overall hyperglycemia in patients with diabetes, suggesting that treatment targeting postprandial glucose in addition to fasting plasma glucose may be able to improve glycemic control.

Insulin degludec/insulin aspart (IDegAsp) is a novel combination drug [70\% insulin degludec (IDeg) and 30\% insulin aspart (IAsp)]. IDeg and IAsp exist separately in solution, allowing formulation as a single injection. After subcutaneous injection, IDeg immediately forms stable multihexamers that create a tissue depot from which IDeg monomers slowly dissociate, while IAsp monomers are rapidly released into the circulation.

Based on the pharmacokinetic and pharmacodynamic profile of IDegAsp, it may be a novel option for BOT that could improve postprandial plasma glucose (although only after one meal a day). However, IDegAsp has a 30\% lower content of basal insulin, suggesting that the fasting plasma glucose level may increase after switching from basal insulin to IDegAsp on a 1: 1 unit basis.

\section{《Aim》}

The present study was carried out to develop an algorithm for safe and effective switching from basal insulin to once-daily insulin IDegAsp in patients with inadequately controlled type 2 diabetes.

\section{《Method》}

This was a prospective, 4-week, single-center, randomized, open-label, parallel-group, treat-to-target study. Between April 2016 and March 2017, patients with type 2 diabetes were recruited at the outpatient clinic of St. Marianna University Hospital (Kawasaki, Japan). Patients were randomly assigned to continue their current basal insulin therapy $(n=10)$ or to switch to IDegAsp on a 1: 1 unit basis $(n=10)$. The insulin dose was titrated weekly at hospital visits or via telephone. Based on the mean self-measured blood glucose (SMBG) level before breakfast during the preceding 7 days, the dose was increased by 2 units if SMBG was $>100 \mathrm{mg} / \mathrm{dL}$ or was reduced by 2 units if it was $<80$ $\mathrm{mg} / \mathrm{dL}$. At baseline and after 4 weeks, a mixed meal test (total caloric content of $460 \mathrm{kcal}$, including 53\% carbohydrate, $16 \%$ protein, and $31 \%$ fat) was performed to evaluate the plasma glucose profile (fasting and $30 \mathrm{~min}, 60 \mathrm{~min}, 90 \mathrm{~min}$, and $120 \mathrm{~min}$ postprandially).

\begin{tabular}{|c|c|c|c|}
\hline & $\begin{array}{c}\text { Basal group } \\
\quad(\mathrm{n}=10)\end{array}$ & $\begin{array}{l}\text { IDegAsp group } \\
\quad(\mathbf{n}=\mathbf{1 0})\end{array}$ & $P$-value \\
\hline Female (n) & 5 & 1 & 0.06 \\
\hline Age (years) & $68 \pm 8$ & $66 \pm 13$ & 0.73 \\
\hline Duration of diabetes (years) & $16 \pm 7$ & $20 \pm 11$ & 0.39 \\
\hline Body mass index $\left(\mathrm{kg} / \mathrm{m}^{2}\right)$ & $28.8 \pm 5$ & $25.8 \pm 5$ & 0.21 \\
\hline Fasting plasma glucose (mg/dL) & $155 \pm 25$ & $144 \pm 37$ & 0.42 \\
\hline HbA1c (\%) & $7.5 \pm 1$ & $7.6 \pm 1$ & 0.60 \\
\hline Systolic blood pressure (mmHg) & $133 \pm 13$ & $132 \pm 16$ & 0.88 \\
\hline Diastolic blood pressure $(\mathrm{mmHg})$ & $80 \pm 11$ & $75 \pm 10$ & 0.30 \\
\hline LDL cholesterol (mg/dL) & $91 \pm 29$ & $89 \pm 40$ & 0.60 \\
\hline HDL cholesterol (mg/dL) & $53 \pm 20$ & $44 \pm 8$ & 0.58 \\
\hline Triglycerides (mg/dL) & $138 \pm 46$ & $124 \pm 47$ & 0.26 \\
\hline Basal insulin at screening (IGlar/IDeg) & $5 / 5$ & $4 / 6$ & 0.64 \\
\hline Basal insulin dose at screening (U/day) & $16.8 \pm 9.4$ & $11.3 \pm 5.3$ & 0.12 \\
\hline
\end{tabular}

\section{《Result》}

There were no differences between the two groups with regard to gender, age, duration of diabetes, body mass index, fasting plasma glucose, HbA1c, blood pressure, and serum lipid profile. After 4 weeks, the mean daily dose of insulin was significantly increased by $60 \%$ in both groups. The SMBG before breakfast was significantly decreased from baseline by $29 \pm 8 \mathrm{mg} / \mathrm{dL}$ in the basal insulin group ( $\mathrm{P}=0.007)$, and was decreased by $18 \pm 9 \mathrm{mg} / \mathrm{dL}$ in the IDegAsp group $(\mathrm{P}=0.328)$.

A)

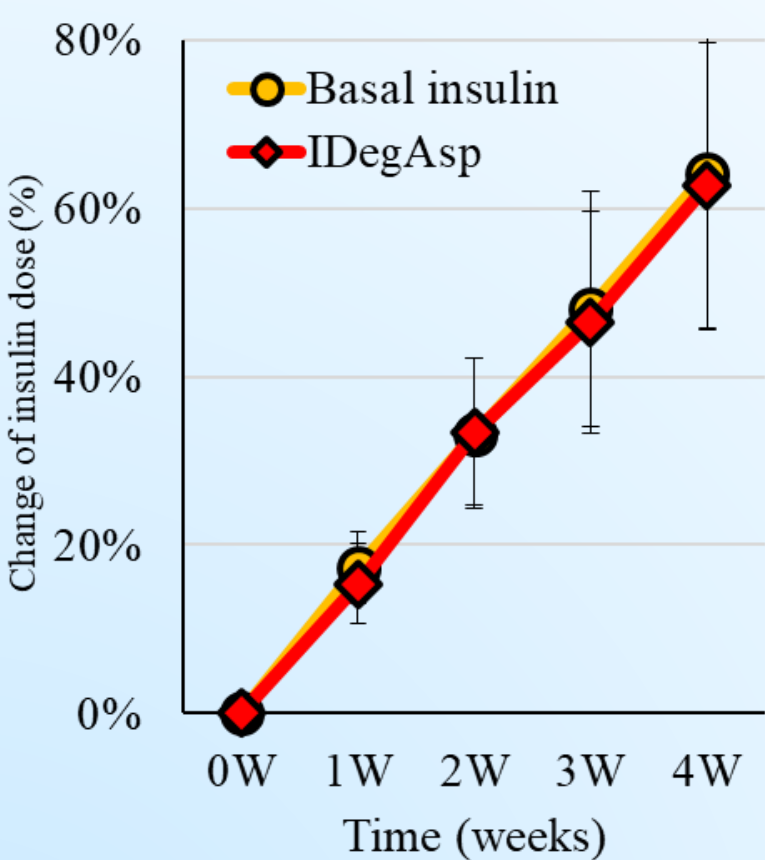

B)

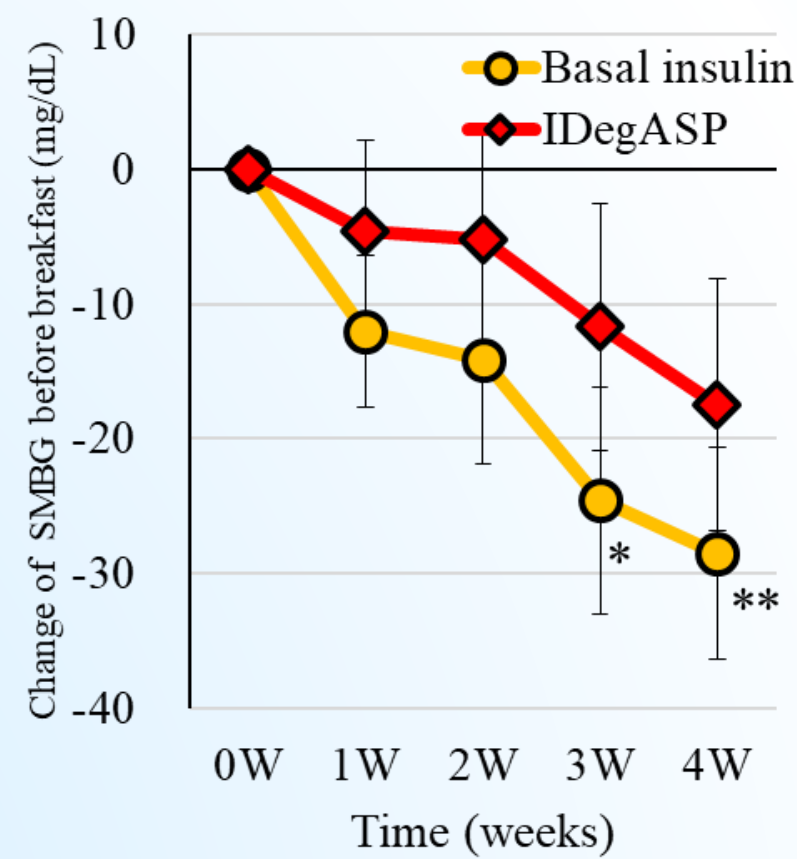

In the meal test, the mean plasma glucose level showed a significant decrease of $22 \pm 6 \mathrm{mg} / \mathrm{dL}$ in the basal insulin group ( $\mathrm{P}=0.008$ vs. baseline) and $49 \pm 7 \mathrm{mg} / \mathrm{dL}$ in the IDegAsp group (P $<0.001$ vs. baseline). The mean estimated treatment difference (IDegAsp group basal insulin group) was $-27.5 \mathrm{mg} / \mathrm{dL}(95 \% \mathrm{CI}-47,-8, \mathrm{p}=0.008)$. After 4 weeks, the glucose $\mathrm{AUC}_{0-2 \mathrm{~h}}$ was $20,300 \pm 4,500 \mathrm{mg} \cdot \mathrm{min} / \mathrm{dL}$ in the basal insulin group ( $\mathrm{P}=0.004$ vs. baseline) and 18,000 $\pm 4,100$ $\mathrm{mg} \cdot \mathrm{min} / \mathrm{dL}$ in the IDegAsp group ( $\mathrm{P}<0.001 \mathrm{vs}$. baseline). The mean estimated treatment difference (IDegAsp group - basal insulin group) was $-2,800 \mathrm{mg} \cdot \mathrm{min} / \mathrm{dL}(95 \% \mathrm{CI}-5,300,-350, \mathrm{p}=0.028)$, confirming that IDegAsp was superior to basal insulin. In the IDegAsp group, the 2-hour postprandial plasma glucose level was significantly decreased from $204 \pm 36 \mathrm{mg} / \mathrm{dL}$ to $133 \pm 40 \mathrm{mg} / \mathrm{dL}$ ( $<<0.001$ ), which was in the fasting plasma glucose range. There were no confirmed hypoglycemic episodes in either group during the 4-week study period.

A) Basal insulin

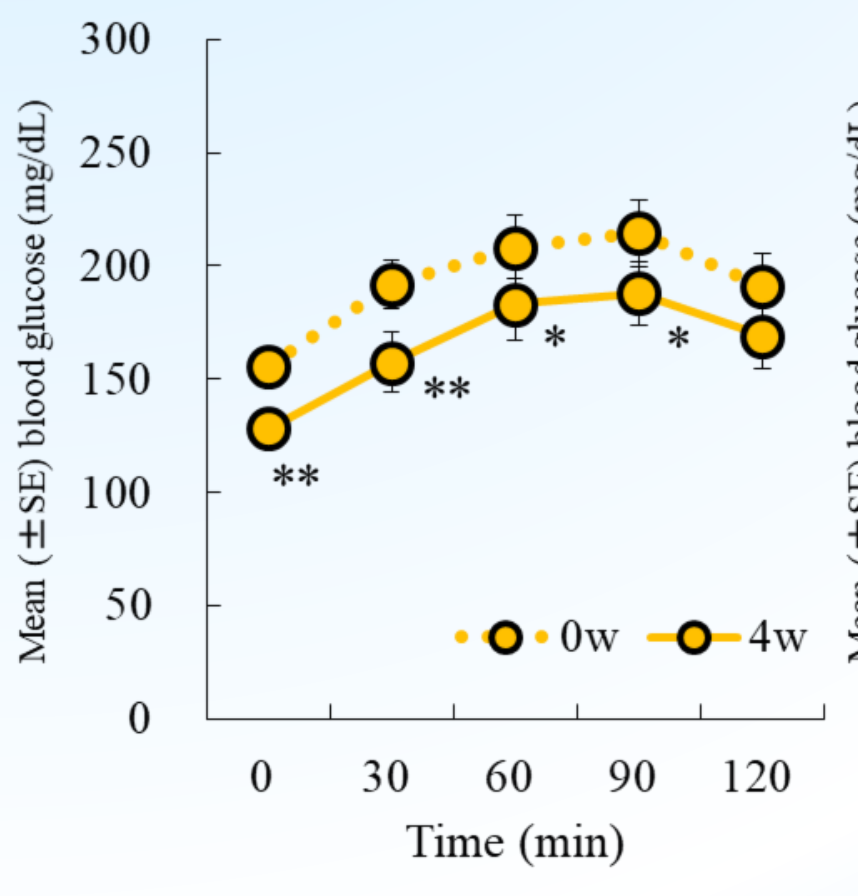

B) IDegAsp

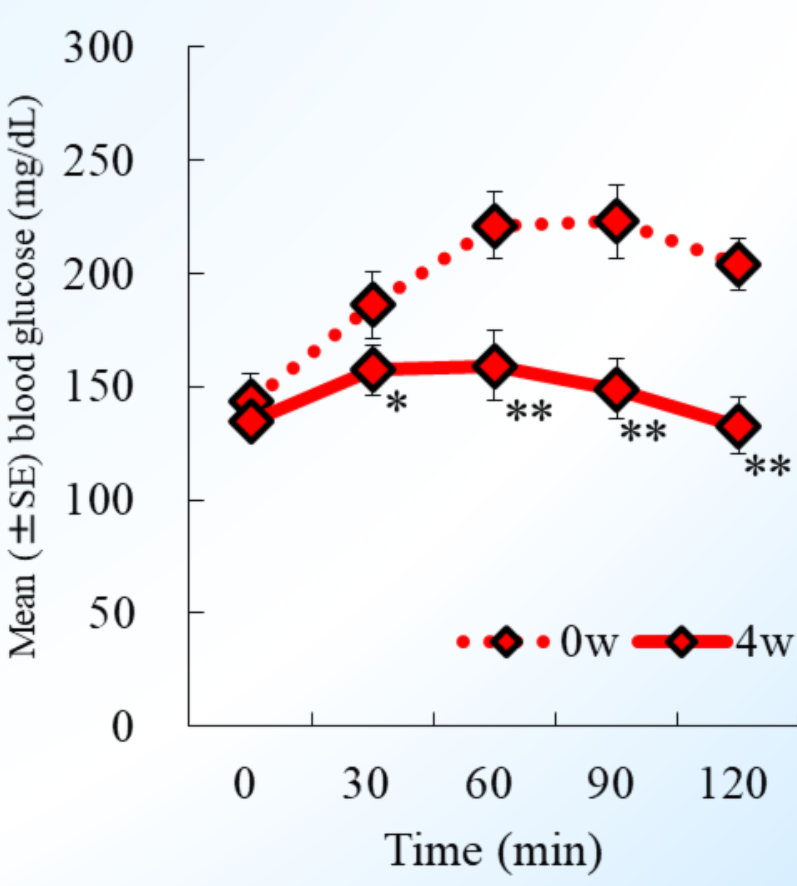

《Conclusions》

After switching from basal insulin, the IDegAsp dose can be up-titrated by $60 \%$ based on fasting plasma glucose data. However, monitoring of postprandial glucose should be considered to minimize the risk of postprandial hypoglycemia when up-titrating the IDegAsp dose beyond $60 \%$. 